\title{
ANÁliSE DA APLICAÇÃo DAS BOAS PRÁTICAS DE FABRICAÇÃO NAS AGROINDÚSTRIAS FAMILIARES DO ARRANJO PRODUTIVO LOCAL DO VALE DO TAQUARI
}

\author{
A.Girelli $^{1 *}$, E.M.Kolchinski ${ }^{2}$, E.Biondo ${ }^{2}$ e V. Sant'Anna ${ }^{2}$
}

\begin{abstract}
${ }^{1}$ Associação Riograndense de Empreendimentos de Assistência Técnica e Extensão Rural - Emater/RS - Associação Sulina de Crédito e Assistência Rural - Ascar, Escritório Municipal de Encantado, RS, Brasil.

${ }^{2}$ Universidade Estadual do Rio Grande do Sul - Unidade de Encantado, RS, Brasil

* Autor correspondente: Escritório Municipal de Encantado. Associação Riograndense de Empreendimentos de Assistência Técnica e Extensão Rural - Emater/RS - Associação Sulina de Crédito e Assistência Rural - Ascar. Rua Monsenhor Scalabrini, 1047, Centro Administrativo Municipal, $1^{\circ}$ Andar, Encantado, RS, CEP: 95960-000 e-mail: girelliandreza@ hotmail.com
\end{abstract}

Resumo - O Vale do Taquari tem por tradição a agroindustrialização na própria propriedade desde os tempos da colonização pelos alemães e italianos. Atualmente, a agroindustrialização é incentivada por meio de políticas públicas e tem papel de relevância na fixação da população na área rural, pela geração de postos de trabalho, aumento da renda e da qualidade de vida. O Arranjo Produtivo Local Agroindústrias Familiares Vale do Taquari é uma política pública que tem por objetivo o fortalecimento do setor de processamento de alimentos. Para que estes empreendimentos sejam bem sucedidos, a qualidade higiênico-sanitária dos produtos oferecidos aos consumidores é fundamental e para alcançar este atributo é necessária a aplicação das normas de Boas Práticas de Fabricação (BPF). Neste contexto, foi avaliada a aplicação das BPF nas vinte e três agroindústrias do APL Agroindústrias Familiares Vale do Taquari, por meio da aplicação de check list. De acordo com os resultados foi possível observar a importância da participação das pessoas envolvidas no processamento de produção em capacitações, concluindo-se que as instruções são eficazes e as agroindústrias familiares necessitam de apoio técnico em BPF para que as melhorias sejam mantidas e ampliadas.

Palavras-chave - Agroindústrias. Arranjos Produtivos Locais. Boas Práticas de Fabricação.

Abstract - The Taquari Valley has traditionally agroindustrialização on the property itself since the days of colonization by Germans and Italians. Currently, agro-industrialization is encouraged through public policies and has paper of relevance in determining the population in rural areas by generating jobs, increasing income and quali-ness of life. The Local Productive Arrangement Agroindús-Doggy Family Taquari Valley is a PU-Republic policy that aims to strengthen the food processing sector. For these in-preendimentos are successful, the sanitary quality of products offered to con- sumers is vital, and to achieve this allo-bution is necessary to apply the standards of Good Manufacturing Practices (GMP). In this context, the application of GMP was evaluated in twenty-three Agroin-dustries APL Agribusiness Family Vale do Taquari, through the application checklist. A-lanyard with the results we observed the im-portant participation of the people involved in the production of processing capabilities, if conclu-going that the instructions are effective and family agroindús-Doggy require technical support in GMP for the improvements are maintained and expanded.

Keywords - Agribusinesses. Local Productive Arrangements. Good Manufacturing Practice.

Recebido em: 09 de dezembro de 2015 Aprovado em: 31 de dezembro de 2015

\section{INTRODUÇÃ̃O}

De acordo com Lagemann (2001), a agroindustrialização teve origem a partir da transformação da propriedade agrícola de subsistência, para uma estrutura de produção de matéria-prima, contudo, as funções de armazenar, processar e distribuir os alimentos eram transferidas para organizações fora da propriedade, que passaram a ser conhecidas como agroindústrias

A agroindustrialização da produção realizada pelos agricultores familiares vem se constituindo em uma importante alternativa de geração de renda no meio rural, onde os produtores utilizam a força de trabalho familiar e a matéria-prima própria, industrializando e comercializando sua produção. Neste tipo de empreendimento os agricultores são os protagonistas do processo, passando a atuar em toda a cadeia produtiva, revertendo a forma de comercialização que se constituía por longa cadeia de intermediários. Além disso, ocorre a descentralização e diversificação da produção, a promoção do desenvolvimento local, o fortalecimento dos valores culturais da região e a oferta de produtos que mantém características de sabores diferenciados.

O Vale do Taquari, em função das etnias predominantes, alemã e italiana, caracteriza-se por industrializar produtos na unidade familiar tanto para o consumo da família bem como para comercializar em pequena escala. Este processamento agrega valor à matéria-prima, gera emprego e renda, aumenta a qualidade de vida no campo e diminui o êxodo rural.

O Programa de Fortalecimento das Cadeias e Arranjos Produtivos Locais define APL como um agrupamento de empresas de um território com particularidades produtivas e com vínculos de interação, cooperação, 
comércio, tecnologia e aprendizagem entre si e com outras instituições locais, como órgãos e entidades públicos, associações, universidades, centros tecnológicos, sindicatos, instituições de crédito, ensino e pesquisa, geradores de externalidades econômicas positivas e de ambiente favorável ao desenvolvimento econômico e social (RIO GRANDE DO SUL, 2011).

O APL das Agroindústrias Familiares do Vale do Taquari compreende treze municípios do Conselho Regional de Desenvolvimento (Corede) do Vale do Taquari, definidos a partir das Microrregiões 1 e 2, formadas no Pré-Território do Codeter do Vale do Taquari: Anta Gorda, Arvorezinha, Coqueiro Baixo, Dois Lajeados, Doutor Ricardo, Encantado, Ilópolis, Muçum, Nova Bréscia, Putinga, Relvado, Roca Sales, Vespasiano Corrêa (REUNIÃO DO CODETER, 2012; REUNIÃO DO CODETER, 2013).

A articulação para o desenvolvimento da atividade de processamento da produção agropecuária passa pela qualidade dos produtos oferecidos. Segundo Tondo e Bartz (2011), a produção de alimentos em escala para comercialização exige cuidados mais apurados para manter suas características até o consumo do que um alimento preparado para uma família e que será consumido em pouco tempo.

Estes cuidados são traduzidos pelas Boas Práticas de Fabricação (BPF), que Segundo a Anvisa, "abrangem um conjunto de medidas que devem ser adotadas pelas indústrias de alimentos a fim de garantir a qualidade sanitária e a conformidade dos produtos alimentícios com os regulamentos técnicos" (AGÊNCIA NACIONAL DE VIGILÂNCIA SANITÁRIA, 2013).

Diante da relevância das BPF, este trabalho busca verificar a sua aplicação nas agroindústrias familiares localizadas nos treze municípios que compõem o APL Agroindústrias Familiares Vale do Taquari.

\section{METODOLOGIA}

Para conhecer a realidade das agroindústrias familiares quanto à aplicação das BPF procedeu-se a coleta de dados com instrumento padronizado, por intermédio de observação. Posterior à coleta, os dados foram analisados e os resultados demonstrados por meio de tabelas, gráficos e texto. Segundo Sampieri, Collado e Lucio (2013), estas características são de enfoque quantitativo. De acordo com os mesmos autores, enfoque quantitativo "utiliza a coleta de dados para testar hipóteses, baseando-se na medição numérica e na análise estatística para estabelecer padrões e comprovar teorias".

Foram visitadas vinte e três agroindústrias, que produzem queijo, aipim descascado e congelado, ervamate, açúcar mascavo; melado líquido e melado batido, rapadura, doces e conservas de frutas e vegetais, embutidos, sucos, vinho, pães, cucas, bolachas e massas.

As visitas nas agroindústrias foram agendadas por intermédio dos escritórios municipais da Emater/RSAscar. O critério para a seleção das agroindústrias foi estarem cadastradas ou em fase de cadastramento no Programa Estadual de Agroindústrias Familiares, esta- rem em funcionamento ou com a estrutura em fase de conclusão.

O levantamento dos dados para a análise foi realizado com check-list previamente elaborado com base na Portaria SVS/MS n 326 , de 30 de julho (BRASIL, 1997); na RDC no 275, de 21 de outubro, da Anvisa (AGÊNCIA NACIONAL DE VIGILÂNCIA SANITÁRIA, 2002) e na Circular do Departamento de Inspeção de Produtos de Origem Animal - DIPOA, Circular $\mathrm{n}^{\circ} 175$, de 16 de maio (BRASIL, 2005).

O check list está dividido em cinco grupos, edificaçãos e instalações; equipamentos, móveis e utensílios; manipuladores; produção e transporte de alimento e documentação. Cada grupo contém subgrupos e estes, diversos itens. A esquematização dos grupos e subgrupos pode ser vizualizada na figura 1.

As visitas foram sempre acompanhadas por um responsável pela agroindústria que mostrava as dependências do estabelecimento e fazia um breve relato do processo produtivo. Em seguida preencheu-se o check list, onde cada item foi marcado com uma das opções: Conforme (C), Não Conforme (NC) ou Dispensa de avaliação (D), de acordo com o aspecto visual do componente observado e/ou pela entrevista com o proprietário

Após a conclusão das visitas, as informações coletadas foram transcritas em planilha do Microsoft Office Excel 2007, que proporcionou a análise dos dados que são apresentadas como resultados deste estágio.

\begin{tabular}{|c|c|c|c|}
\hline \multicolumn{4}{|c|}{ GRUPOI-EDIFICACCAOEINSIALACCOES } \\
\hline AREA EXIERNA & $\begin{array}{l}\text { PAREDESE } \\
\text { DIVISORIAS }\end{array}$ & $\begin{array}{l}\text { ILUMINACCAOE } \\
\text { INSTALACAO } \\
\text { ELETRICA }\end{array}$ & $\begin{array}{l}\text { MANEIODOS } \\
\text { RESIDUOS }\end{array}$ \\
\hline ACESSO & PORTAS & $\begin{array}{l}\text { VENTILACAOE } \\
\text { CLIMATIZACCAO }\end{array}$ & $\begin{array}{l}\text { ESGOTAMENTO } \\
\text { SANITARIO }\end{array}$ \\
\hline AREA INTERNA & $\begin{array}{l}\text { JANELASE OUTRAS } \\
\text { ABERTURAS }\end{array}$ & $\begin{array}{l}\text { HIGIENIZAÇAODAS } \\
\text { INSTALACOES }\end{array}$ & $\begin{array}{l}\text { LEIAUTE } \\
\end{array}$ \\
\hline : & \begin{tabular}{|l|} 
INSTALACOES \\
SANITARIAS E \\
VESTIARIOS
\end{tabular} & $\begin{array}{l}\text { CONTROLE } \\
\text { INTEGRADO DE } \\
\text { VETORES E PRAGAS } \\
\text { URBANAS }\end{array}$ & \\
\hline TETOS & $\begin{array}{l}\text { LAVATORIOS NA } \\
\text { AREA DE } \\
\text { PRODUÇAO }\end{array}$ & $\begin{array}{l}\text { ABASTECIMENTODE } \\
\text { AGUA }\end{array}$ & \\
\hline \multirow{3}{*}{$\begin{array}{c}\text { GRUPO 2- } \\
\text { EQUIPAMENTOS, } \\
\text { MOVEIS E } \\
\text { UTENSILIOS } \\
\text { EQUIPAMENTOS }\end{array}$} & & & \\
\hline & $\begin{array}{c}\text { GRUPO 3- } \\
\text { MANIPULADORES }\end{array}$ & $\begin{array}{l}\text { GRUPO 4- } \\
\text { PRODUCCAOE E } \\
\text { TRANSPORTE DE } \\
\text { ALIMENTO }\end{array}$ & $\begin{array}{c}\text { GRUPO 5- } \\
\text { DOCUMENTACุAO }\end{array}$ \\
\hline & VESTUARIO & MATERIA-PRIMA & $\begin{array}{l}\text { MANUAL DE BOAS } \\
\text { PRATICAS DE } \\
\text { FABRICACAO }\end{array}$ \\
\hline \multirow{4}{*}{ 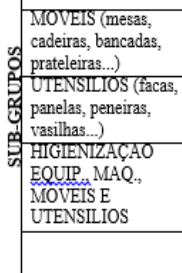 } & $\begin{array}{l}\text { HABITOS } \\
\text { HIGIENICOS }\end{array}$ & $\begin{array}{l}\text { INGREDIENTES E } \\
\text { EMBALAGENS }\end{array}$ & $\begin{array}{l}\text { PROCEDIMENTOS } \\
\text { OPERACIONAIS } \\
\text { PADRONIZADOS }\end{array}$ \\
\hline & ESTADODE SAUDE & $\begin{array}{l}\text { ARMAZENAMENTO } \\
\text { PRODUTO FINAL }\end{array}$ & $\begin{array}{l}\text { CURSODE BOAS } \\
\text { PRATICAS DE } \\
\text { FABRICACCAO } \\
\end{array}$ \\
\hline & & $\begin{array}{l}\text { CONTROLE DE } \\
\text { QUALIDADE DO } \\
\text { PRODUTO FINAL }\end{array}$ & \\
\hline & & $\begin{array}{l}\text { TRANSPORTE DO } \\
\text { PRODUTO FINAL }\end{array}$ & \\
\hline
\end{tabular}

Figura 1 - Esquematização dos itens do check list aplicado no estudo.

\section{RESULTADOS E DISCUSSÃO}

Os resultados são apresentados em forma de texto e/ou gráficos, com os percentuais relativos a conformidades, não conformidades e dispensa de avaliação dos itens.

As conformidades referem-se aos itens que atendem aos atributos avaliados, as não conformidades aludem aos itens que não atendem aos atributos na sua totalidade, uma vez que alguns itens são compostos por 
mais de uma característica. A opção dispensa de avaliação foi marcada nos casos em que o item não podia ser avaliado devido à agroindústria estar em fase de construção, reforma ou ampliação, por ainda não ter iniciado as suas atividades e nos casos em que o item não dizia respeito ao processo produtivo em questão.

\subsection{Tipo de inspeção e curso de boas práticas de fa- bricação}

Das vinte e três agroindústrias, 56,52\% tem inspeção pela Coordenadoria de Saúde; $17,39 \%$ pelo Sistema de Inspeção Municipal (SIM); 13,04\% pelo Mapa; 4,35\% pela CISPOA; 4,35\% têm dois registros, Mapa e Coordenadoria de Saúde, pois produzem bebidas e também produtos de origem vegetal e 4,35\% não tem registro, conforme pode ser observado na figura 2

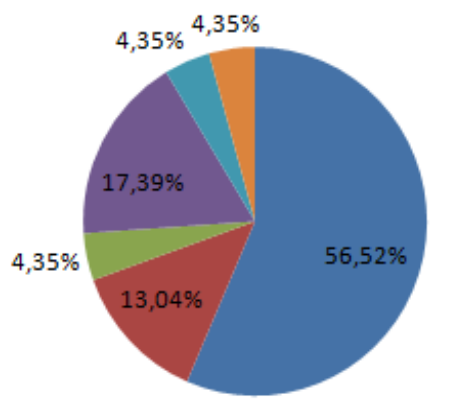

- Coord.Saúde
" Mapa
" Cispoa
- Sim
- Sem Registro
- Coord.Saúde/Mapa

Figura 2 - Tipos de Inspeção das agroindústrias

Do total das agroindústrias visitadas, $73,91 \%$ têm, no mínimo, uma pessoa que realizou curso de BPF, sendo que $52,17 \%$ possuem curso de 16 horas e $21,74 \%$ de 40 horas. O curso de BPF não foi realizado por $26,09 \%$ das agroindústrias. A figura 3 ilustra esses dados.

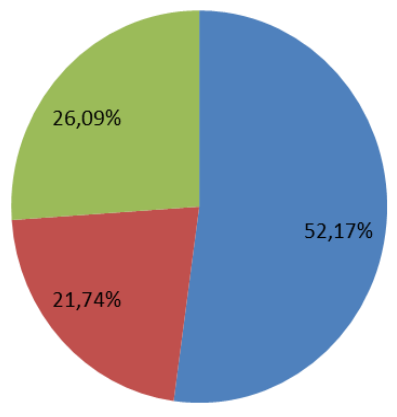

Figura 3 - Carga horária do curso de BPF realizado pelas agroindústrias.

Das agroindústrias inspecionadas pela Coordenadoria de Saúde, 69,23\% fizeram curso de BPF de 16 horas, $23,08 \%$ não realizaram curso e $7,69 \%$ fizeram curso de 40 horas. Cem por cento das agroindústrias inspecionadas pelo Mapa possuem curso de BPF de 40 horas. Das inspecionadas pelo SIM, $50 \%$ fizeram curso de 16 horas, $25 \%$ fizeram de 40 horas e $25 \%$ não possuem curso. A tabela 1 demonstra estes resultados:
Tabela 1 - Órgão de inspeção x carga horária de curso de BPF.

\begin{tabular}{l|l|l|l}
\hline \multirow{2}{*}{ Inspeção } & \multicolumn{3}{|l}{ Carga Horária Curso BPF - horas } \\
\cline { 2 - 4 } & 40 & 16 & sem curso \\
\hline Coord. Saúde & $7,69 \%$ & $69,23 \%$ & $23,08 \%$ \\
\hline Mapa & $100 \%$ & $0,00 \%$ & $0 \%$ \\
\hline SIM & $25 \%$ & $50 \%$ & $25 \%$ \\
\hline Sem registro & $0 \%$ & $0 \%$ & $100 \%$ \\
\hline Mapa/Coord. Saúde & $0 \%$ & $0 \%$ & $100 \%$ \\
\hline Cispoa & $0 \%$ & $100 \%$ & $0 \%$ \\
\hline
\end{tabular}

\subsection{Análise geral dos grupos}

Analisando os resultados dos grupos, temos com maior percentual de inconforidades a parte de documentação, que está subdividida em Manual de BPF e POPs. Os demais grupos apresentam entre $54 \%$ e $63 \%$ de conformidades. Estes dados expressam a média de todos os itens que os compõem e podem ser visualizados na figura 4.

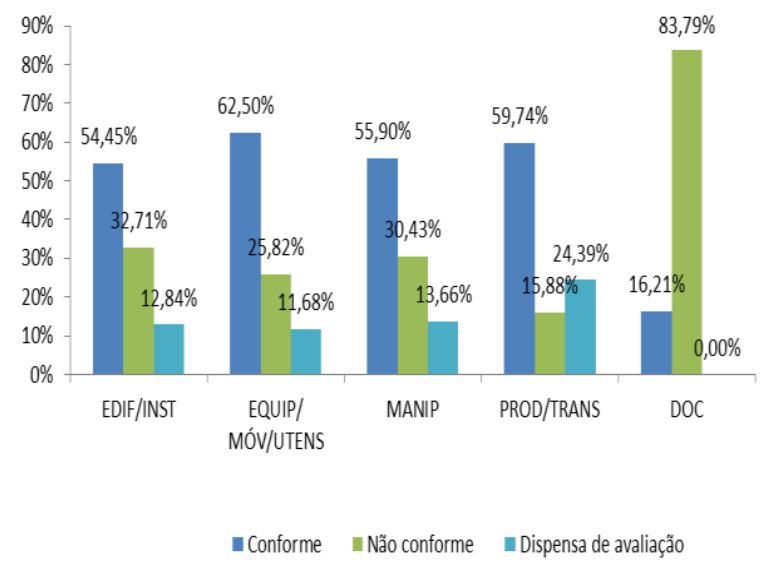

Figura 4 - Percentuais referentes aos grupos do check list

Dentre os grupos, o que teve maior percentual de inconformidades foi o da documentação, 83,79\% e o que teve maior índice de conformidades foi o grupo equipamentos, móveis e utensílios, $62,50 \%$. Isto, provavelmente se deve ao fato de que essas agroindústrias são gerenciadas por pessoas que sempre concentraram seus esforços no fazer, no realizar, no aprender fazendo e na tradição passada de geração em geração, ficando a parte da escrita relegada ao segundo plano, mas aos poucos o cenário vai se alterando e a gestão dos empreendimentos vai tomando nova forma, que inclui planejamento e registros, não apenas pela imposição das legislações, mas por serem percebidas úteis e necessárias. 


\subsection{Análise do grupo edificação e instalações}

Edificação e instalações abrangem área externa, acesso à agroindústria, pisos, tetos, paredes, divisórias, portas, janelas, banheiros, vestiários, lavatórios, iluminação, ventilação, higienização, controle de pragas, abastecimento de água, manejo de resíduos, esgoto sanitário e o leiaute.

$\mathrm{Na}$ área externa o item que mais apresentou inadequações foi referente às vias de acesso, onde a maioria das inconformidades se deve ao pavimento de terra, sem nenhum revestimento.

$\mathrm{O}$ acesso às agroindústrias é na maior parte exclusivo, apenas 30,43\% tem acesso comum a outros usos e, geralmente, é o mesmo da residência da família.

No que se refere a pisos, tetos, paredes, divisórias, portas, janelas e outras aberturas, a figura 5 ilustra o percentual de conformidades, não conformidades e dispensa de avaliação de cada um deles.

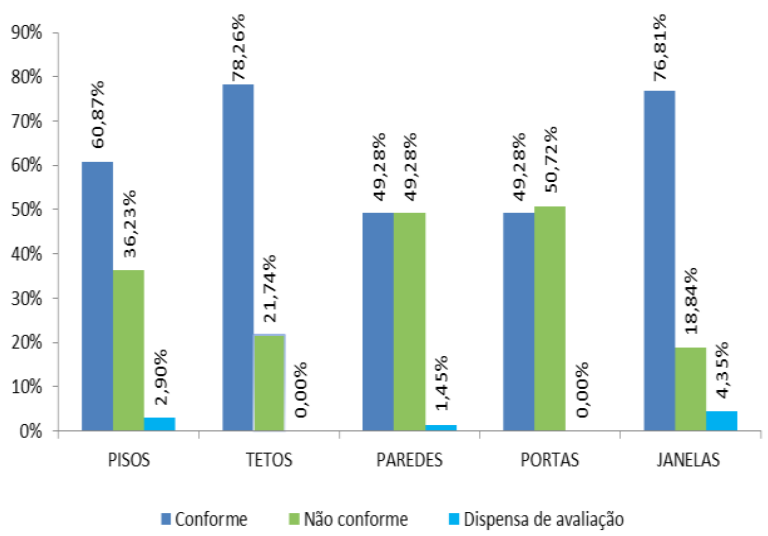

Figura 5 - Pisos, tetos, paredes, divisórias, portas, janelas e outras aberturas.

As não conformidades destes subitens se referem basicamente à reforma ou edificação não concluída em algumas agroindústrias e outros casos são de fácil solução, como arrumar uma tela que desprendeu, trocar um vidro que quebrou. Referente às portas, apenas uma agroindústria tinha porta com fechamento por mola, as demais era com fechamento manual, porém a circulação de pessoas nas agroindústrias familiares é pequena, haja vista, serem poucos os manipuladores, portanto uma exigência que poderia ser revista para esta categoria de processadores. As paredes, em alguns casos, precisam ser pintadas com tinta epóxi ou receber revestimento impermeável e de fácil higienização até a altura mínima de 2 metros, como preconiza a legislação.

Nos banheiros e vestiários, 73,91 \% são isolados da área de produção e tem passagem coberta e calçada que protegem o acesso, porém 78,26\% não têm banheiro separado para cada sexo. A legislação exige banheiros separados, porém, em se tratando de agroindústrias familiares onde trabalham poucas pessoas, em alguns casos apenas um casal, essa exigência é questionável.

Todos os banheiros concluídos tinham torneira de acionamento manual. Os pisos e paredes estavam $78,26 \%$ adequados e em estado satisfatório de conservação e 95,65\% tinham iluminação e ventilação adequa- das. Papel higiênico e produtos para higiene, como sabonete líquido inodoro e anti-séptico e toalha de papel não reciclado ou outra forma higiênica para secar as mãos tiveram $69,57 \%$ de inadequações, assim como as lixeiras, que 56,52\% eram de acionamento manual. Aviso de procedimento de lavagem das mãos e armários individuais para todos os manipuladores também foram itens que tiveram maioria de não conformidades, $95,65 \%$ e $91,30 \%$ respectivamente. A organização dos banheiros e vestiários foi um quesito que teve $56,52 \%$ de não conformidades e $39,13 \%$ dos banheiros para visitantes eram os mesmos da residência da família que fica próxima da agroindústria. Chuveiros com água quente e fria é atendido em $60,87 \%$ das agroindústrias.

Lavatórios na área de produção tiveram percentuais de conformidades baixos, conforme demonstra a figura 6. Em alguns casos não havia lavatório na área de produção, e quando havia, os requisitos menos atendidos foram torneira com acionamento automático ou pedal, papel toalha não reciclado e coletor sem contato manual.

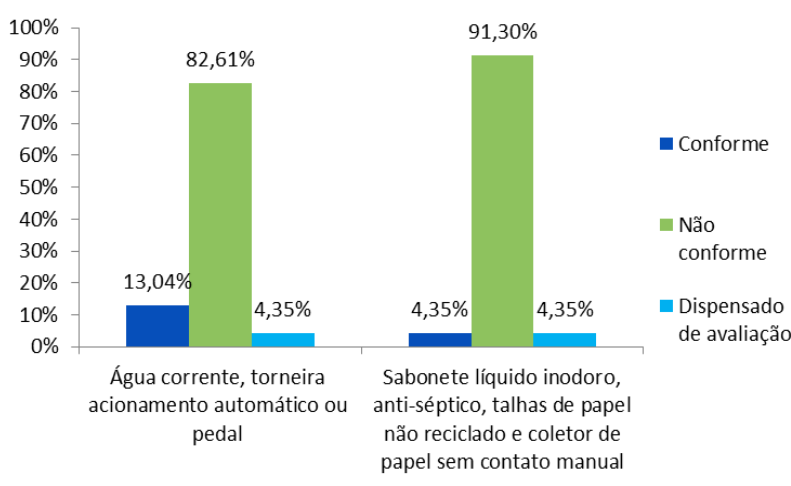

Figura 6 - Lavatórios na área de produção.

Pontos para lavar as mãos em lugares estratégicos na área de produção é um item muito importante para as BPF. As não conformidades verificadas nestes itens são de fácil solução, pois em alguns estabelecimentos havia até mesmo o ponto de água, faltando apenas colocar a pia. Sabonete, papel toalha e lixeira com acionamento não manual também são fáceis de resolver, pois não exigem grande investimento. Em muitos casos o que falta é orientação.

A Iluminação e as instalações elétricas, exceto por $21,74 \%$ em que a fiação está aparente, estão em conformidade e $1,45 \%$ das agroindústrias não estão prontas ou o prédio está passando por alguma reforma que interfere na parte elétrica. Ventilação e climatização ficam na maior parte como dispensados de avaliação, pois são poucas as agroindústrias que usam aparelhos para regular a temperatura do ambiente. Dos 39,13\% que utilizam $27,83 \%$ estão conformes e as inadequações são na maioria por falta de registro da limpeza dos equipamentos.

Em 65,22\% das agroindústrias a higienização está apropriada e em 59,42\% o manejo dos resíduos está em conformidade, sendo que as principais inadequações são lixeiras sem identificação e com tampa de acionamento manual. Não há grande acúmulo de resíduos na área de 
processamento, pois assim que se encerram as atividades os resíduos são recolhidos e a maior parte é destinada para alimentação animal ou compostagem. O esgoto sanitário está $100 \%$ conectado à fossa e sumidouros.

Na maior parte das agroindústrias, 91,30\%, a água é proveniente de poço artesiano da comunidade, que foi considerado como rede pública no check list, e 34,78\% não têm reservatório de água. Somente $47,83 \%$ têm responsável capacitado para a higienização do reservatório ou contrato com empresa especializada, em 13,04\% dos casos são os próprios proprietários que fazem a higienização, porém sem nenhum treinamento para a execução.

O controle integrado de vetores e pragas urbanas apresenta conformidade em 57,97\% das agroindústrias. Algumas empresas não adotam nenhuma medida de controle, outras têm controle, mas não por empresa especializada, o próprio proprietário adota algumas medidas de prevenção e correção.

Embora a área construída das agroindústrias não seja muito grande, em média $130 \mathrm{~m}^{2}$, o leiaute apresentou $85,51 \%$, de conformidades. Na Figura 7 é possível verificar o percentual individual dos itens avaliados quanto ao leiaute das agroindústrias.

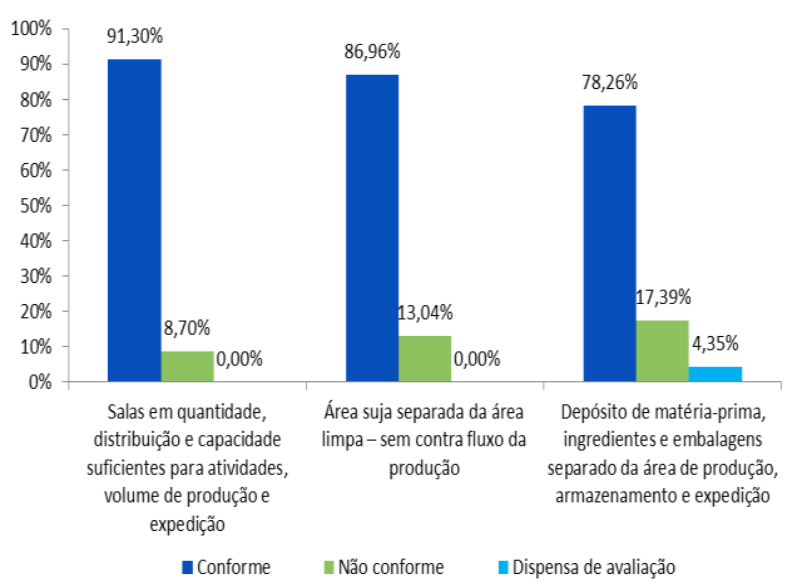

Figura 7 - Leiaute.

\subsection{Análise do grupo equipamentos móveis e utensí- lios}

Os equipamentos, móveis, utensílios e a higienização dos mesmos tiveram o maior percentual de conformidade dos grupos avaliados. Nos utensílios o percentual de dispensado de avaliação foi elevado por duas razões, não havia utensílios naquele momento na agroindústria, não sendo possível a avaliação ou o processo não exigia o uso de utensílios. No caso dos móveis, muitas agroindústrias não tinham móveis, somente máquinas e equipamentos o que contribuiu para que os percentuais de dispensados de avaliação e de não conformidades fossem iguais. Na Figura 8 percebe-se o resultado deste grupo.

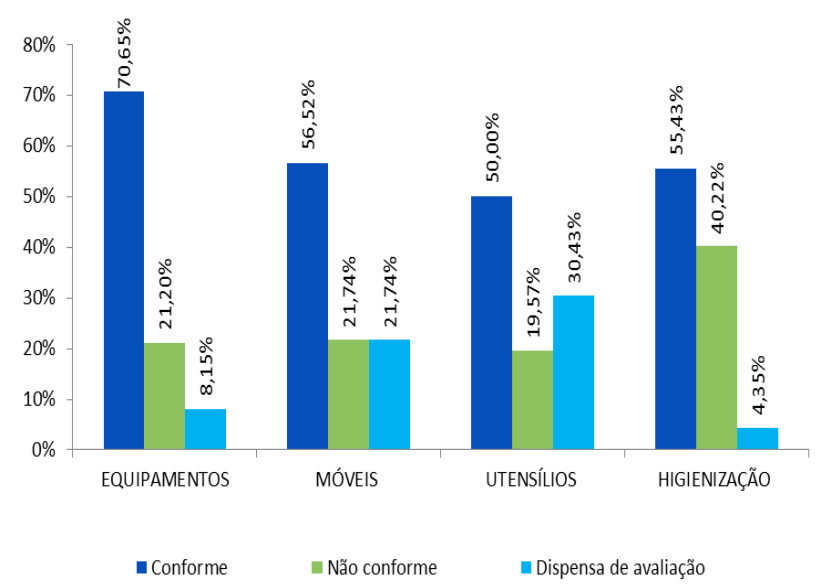

Figura 8 - Equipamentos, móveis, utensílios e higienização dos mesmos.

No subgrupo equipamentos, o item: apropriados para o tipo de produto e em quantidade adequada apresentou $95,65 \%$ de conformidades e o item superfícies em contato com alimento, lisas, íntegras, impermeáveis, resistentes à corrosão, de fácil higienização e material não contaminante, apresentou conformidade de $91,30 \%$. A disposição dos equipamentos e o estado de conservação e funcionamento dos mesmos contaram com $73,91 \%$ de conformidades. Os itens que tiveram mais inconformidades foram referentes ao registro das temperaturas, $78,26 \%$, e anotações da manutenção preventiva dos equipamentos, $39,13 \%$.

Os móveis tiveram inconformidades basicamente devido ao material utilizado, que em alguns casos era madeira, embora a maior parte não tivesse contato direto com o alimento, como cadeiras, armários de utensílios, armário para uniformes, etc.

No item higienização, 4,35\% das agroindústrias não puderam ser avaliadas por ainda não estarem processando alimentos ou por não estar com a edificação finalizada. Onde pode ser observada, verificou-se que dentro deste item a atenção maior está na aquisição dos produtos, pois $73,91 \%$ tinham rótulo regularizado pelo Ministério da Saúde, porém somente $47,83 \%$ das agroindústrias guardavam estes produtos em local adequado, sendo que o adequado na maioria dos casos era a residência da família, ficando em situação de inconformidade as situações em que eram guardados no vestiário, banheiro, ou até mesmo junto com a matéria-prima e embalagens.

\subsection{Análise do grupo manipuladores}

Os manipuladores tiveram conformidade de 55,90\%, inconformidades de $30,43 \%$ e de dispensa de avaliação de $13,66 \%$, conforme consta na figura 9 . O percentual de dispensa de avaliação se refere às situações em que não havia processamento na agroindústria no momento da visita e nem indícios que demonstrassem o comportamento dos mesmos. 


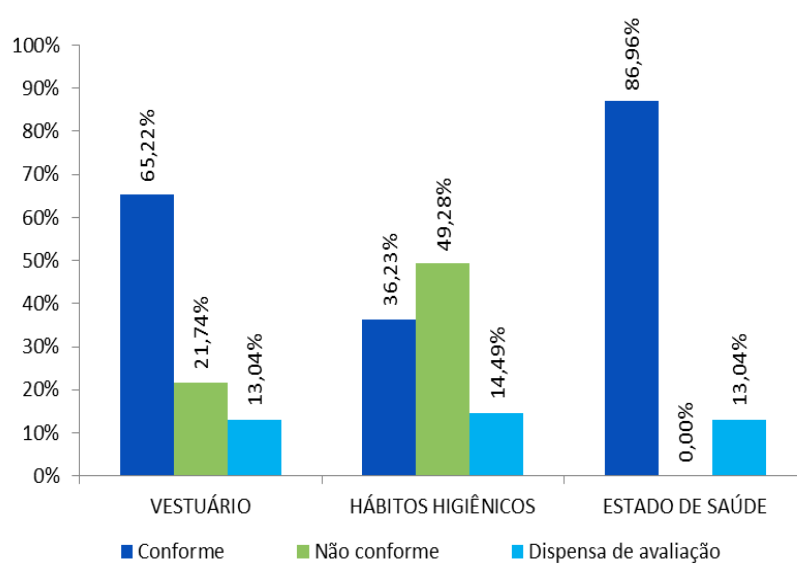

Figura 9 - Itens referentes aos manipuladores.

O baixo percentual de conformidades se deve principalmente por algumas agroindústrias não ter lavatório na área de produção, dificultando que o item de lavagem das mãos após a interrupção de atividades fosse cumprido. A inexistência de cartazes sobre a correta lavagem das mãos e demais hábitos de higiene afixados em locais apropriados contou com $91,30 \%$ de inconformidades.

O estado de saúde dos manipuladores teve $86,96 \%$ de conformidades e $13,04 \%$ de dispensa de avaliação e nenhum caso de inconformidade. Este item foi avaliado pela aparência dos manipuladores e observação visual das mãos e braços. O percentual de dispensa de avaliação se refere às situações onde não foi possível fazer a observação de todos os envolvidos no processamento, por não estarem todos os funcionários ou familiares na agroindústria no momento da visita.

\subsection{Análise do grupo produção e transporte de ali- mento}

Sobre a produção e transporte de alimento, a figura 10 exibe os resultados dos itens avaliados.

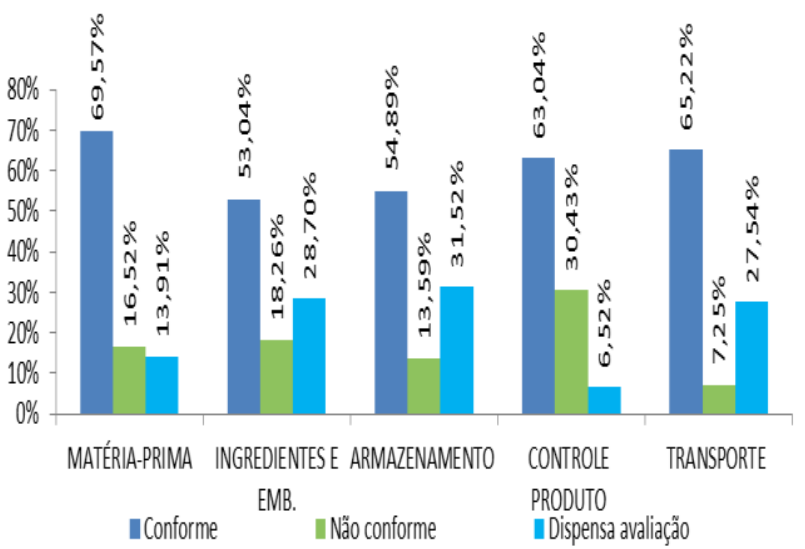

Figura 10 - Percentuais referentes à produção e transporte de alimento.

Referente à matéria-prima, a recepção em local protegido conta com $86,96 \%$ e a inspeção na recepção com $82,61 \%$ de conformidades. No item armazenamento da matéria-prima em local adequado e organizado, os percentuais de conformidades e não conformidades são iguais, 47,83\%. Com $95,65 \%$ de conformidades o item uso obedecendo a ordem de entrada é o que tem melhor atendimento à legislação neste subgrupo. No item rede de frio adequada ao volume e aos diferentes tipos de matérias-primas, a dispensa de avaliação sobressai com $65,22 \%$, tendo em vista que a maior parte das matériasprimas não necessita de armazenamento térmico. As que necessitam, tem rede de frio adequada, não apresentando inconformidades para este item.

Ingredientes e embalagens têm lugar para recepção protegido e isolado da área de produção em $73,91 \%$ das agroindústrias e $86,96 \%$ utilizam os ingredientes pela ordem do prazo de validade, mas requisitos como armazenamento em local limpo e organizado, sobre estrados ou estantes bem conservados, distantes do piso, da parede e do teto permitindo higienização, iluminação e circulação de ar têm percentual de inconformidade de $47,83 \%$. A rede de frio adequada ao volume e tipo de ingredientes é dispensada de avaliação em $82,61 \%$ dos estabelecimentos, pois os ingredientes e embalagens não necessitam de controle térmico.

Na tabela 2 é possível verificar os resultados apurados referente ao armazenamento do produto final.

Tabela 2 - Itens do armazenamento do produto final.

\begin{tabular}{l|c|c|c}
\hline REQUISITOS & $\mathrm{C}$ & $\mathrm{NC}$ & $\mathrm{D}$ \\
\hline $\begin{array}{l}\text { Acondicionado em embala- } \\
\text { gem adequada éntegra }\end{array}$ & $78,26 \%$ & $4,35 \%$ & $17,39 \%$ \\
\hline $\begin{array}{l}\text { Separados por tipo ou grupo } \\
\text { Sobre paletes ou estantes bem } \\
\text { conservados, distantes do } \\
\text { piso, da parede e do teto per- } \\
\text { mitindo higienização, ilumi- } \\
\text { nação e circulação de ar }\end{array}$ & $69,57 \%$ & $17,39 \%$ & $13,04 \%$ \\
\hline $\begin{array}{l}\text { Ausência de material estra- } \\
\text { nho, estragado ou tóxico }\end{array}$ & $78,26 \%$ & $8,70 \%$ & $13,04 \%$ \\
\hline $\begin{array}{l}\text { Local limpo e conservado } \\
\text { Controle e registro de tempe- } \\
\text { ratura para ambiente com } \\
\text { controle térmico }\end{array}$ & $4,35 \%$ & $26,09 \%$ & $69,57 \%$ \\
\hline $\begin{array}{l}\text { Ambiente com controle térmi- } \\
\text { co adequado ao volume e aos } \\
\text { diferentes tipos de alimentos }\end{array}$ & $30,43 \%$ & $0,00 \%$ & $69,57 \%$ \\
\hline $\begin{array}{l}\text { Produtos avariados, com pra- } \\
\text { zo de validade vencido, de- } \\
\text { volvidos ou recolhidos do } \\
\text { mercado devidamente identi- } \\
\text { ficados e armazenados em } \\
\text { local separado e de forma } \\
\text { organizada }\end{array}$ & $34,78 \%$ & $17,39 \%$ & $47,83 \%$ \\
\hline
\end{tabular}

O armazenamento dos produtos prontos tem $54,89 \%$ de conformidades, $13,59 \%$ de não conformidades e $31,52 \%$ de dispensa de avaliação.

O controle da qualidade do produto final é feito quase sempre pela prova de um exemplar do produto, são poucos os casos em que o produto passa por algum tipo de análise química. E estando o produto de acordo com a avaliação dos provadores, nem sempre é mantido algum exemplar para acompanhamento do lote. Os per- 
centuais dos requisitos do item sobre controle de qualidade do produto final estão ilustrados na figura 11. Os percentuais de dispensa de avaliação de referem às agroindústrias que ainda não estão em funcionamento.

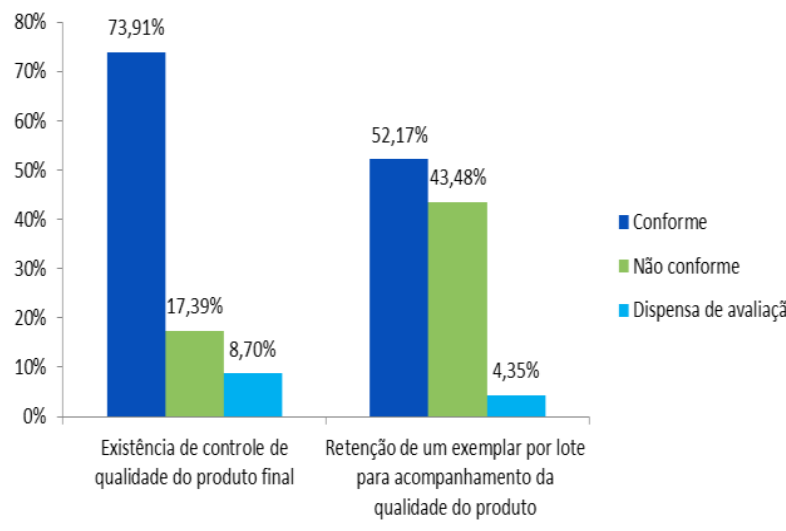

Figura 11 - Qualidade do produto final.

O transporte do produto final é feito em veículo limpo, com cobertura para proteção de carga e que não transporta outras cargas que comprometam a segurança em $91,30 \%$ dos casos e 73,91\% das situações não necessitam de controle de temperatura para o transporte, sendo consideradas dispensadas de avaliação.

\subsection{Análise do grupo documentação}

A parte documental das BPF, POPs e Manual estão com percentual de inconformidade bastante alto, como se pode verificar na figura 12 . Este resultado pode ser o reflexo do curso de BPF de 16 horas, que não habilita o participante a fazer o manual e os POPs. Nas agroindústrias onde tem manual de BPF e os POPs, em alguns casos estes documentos foram redigidos por pessoas que não acompanham o cotidiano do estabelecimento, ficando mais como um atendimento à legislação do que uma ferramenta de qualidade.

Outro ponto que não é atendido em relação ao que exige a RDC $\mathrm{n}^{\circ}$ 275, da Anvisa (AGÊNCIA NACIONAL DE VIGILÂNCIA SANITÁRIA, 2002) é o registro da execução, do monitoramento e dos ajustes dos POPs, em planilhas ou documentos.

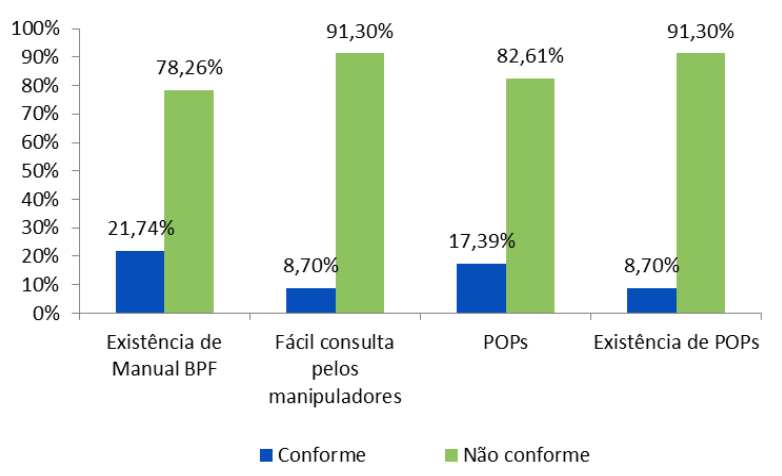

Figura 12 - Manual de BPF e POPs

\subsection{Curso BPF $x$ inconformidades}

Das vinte e três agroindústrias visitadas e dos cento e vinte e dois itens de BPF avaliados, obteve-se o seguinte cenário: $52,17 \%$ dos estabelecimentos têm curso de BPF de 16 horas e apresentaram 33,68\% dos itens com inconformidades; $21,74 \%$ dos estabelecimentos têm alguém com curso de BPF de 40 horas e apresentaram $33,79 \%$ dos itens com inconformidades e $26,09 \%$ dos estabelecimentos não têm curso de BPF e tiveram $50,83 \%$ dos itens com inconformidades. A figura 13 ilustra estes resultados.

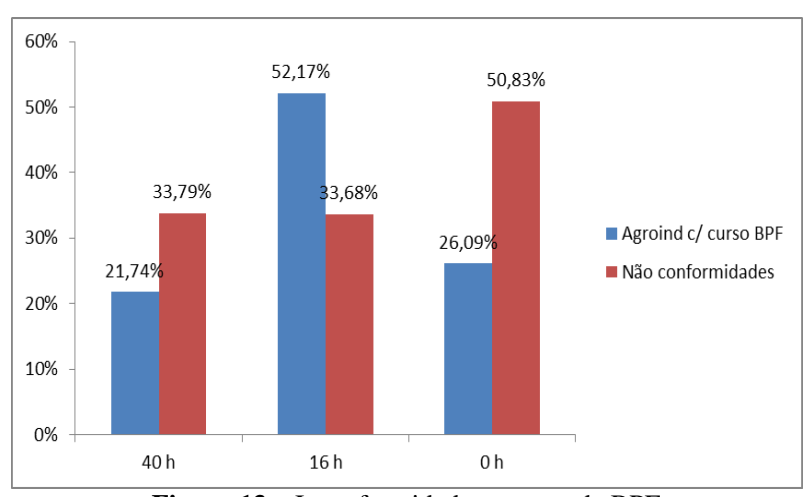

Figura 13 - Inconformidades $\mathrm{x}$ curso de BPF

Embora, a primeira vista não haja diferença entre o percentual de inconformidades das agroindústrias com 16 horas de curso para as que fizeram 40 horas de curso, não é possível fazer esta afirmação, uma vez que o número de agroindústrias com 16 horas de curso é superior ao número de agroindústrias com 40 horas. Entretanto, é possível afirmar que o índice de não conformidades nas agroindústrias onde ninguém fez o curso é maior do que nas agroindústrias onde alguém fez, pois a quantidade de agroindústrias sem curso e com curso de 16 horas é bem aproximado.

Os dados mostram que as agroindústrias familiares com algum curso de BPF se encaixam no grupo 2, de acordo com a RDC 275, da Anvisa (BRASIL, 2002), em que as empresas apresentam entre 51 e $75 \%$ de conformidades, enquanto as agroindústrias que não apresentam funcionários capacitados em BPF se enquadram no grupo 3, onde há entre 0 e $50 \%$ de conformidades no seu processo produtivo.

\section{CONCLUSÃO}

Curso de capacitação em BPF reduz as inconformidades higiênico-sanitárias nas agroindústrias, porém, a partir deste estudo não foi possível determinar se a carga horária do curso influencia nos percentuais.

$\mathrm{O}$ item com maior índice de inconformidade foi lavatório na área de produção, seguidos pela parte referente à documentação, manual de BPF e POPs. Os itens com maiores percentuais de conformidades foram esgotamento sanitário, estado de saúde dos manipuladores e transporte dos produtos prontos.As ações de instruções são eficazes e as agroindústrias familiares necessitam de apoio técnico em BPF para que as melhorias sejam mantidas e ampliadas. 


\section{REFERÊNCIAS}

AGÊNCIA NACIONAL DE VIGILÂNCIA

SANITÁRIA. Alimentos. 2013. Disponível em:

<http://www.anvisa.gov.br/alimentos/bpf.htm>. Acesso em: 12 out. 2013.

\section{AGÊNCIA NACIONAL DE VIGILÂNCIA}

SANITÁRIA. Resolução da Diretoria Colegiada da Agência Nacional de Vigilância Sanitária - RDC no 275, de 21 de outubro de 2002. Dispõe sobre o Regulamento Técnico de Procedimentos Operacionais Padronizados aplicados aos Estabelecimentos Produtores/ Industrializadores de Alimentos e a Lista de Verificação das Boas Práticas de Fabricação em Estabelecimentos Produtores/Industrializadores de Alimentos. Disponível em:

<http://portal.anvisa.gov.br/wps/wcm/connect/dcf7a900 474576fa84cfd43fbc4c6735/RDC+N\%C2\%BA+275\%2 $\mathrm{C}+\mathrm{DE}+21+\mathrm{DE}+\mathrm{OUTUBRO}+\mathrm{DE}+2002 . \mathrm{pdf} ? \mathrm{MOD}=\mathrm{AJP}$ ERES>. Acesso em 22 out. 2013.

BRASIL. Ministério da Agricultura, Pecuária e Abastecimento. Circular no 175/2005 /CGPE/DIPOA. Procedimentos de Verificação dos Programas de Autocontrole. 2005. Disponível em:

$<$ http://www.google.com.br/url?sa=t\&rct=j\&q=\&esrc=s \&source $=$ web\&cd=1\&ved $=0$ CCsQFjAA\&url $=h$ ttp $\% 3 \mathrm{~A}$ $\% 2 \mathrm{~F} \% 2 \mathrm{Fwww}$.agricultura.gov.br\%2Farq editor\%2Ffile \%2FAniamal $\% 2$ FQualidade $\% 2520$ dos $\% 2520$ alimentos \%2FCircular\%2520175.doc\&ei=2rtmUofmIo_Q9ASXn IGAAg\&usg=AFQjCNEiDbm2sG2zjPp197JKsMXBo WpPWA\&bvm=bv.55123115,d.eWU>. Acesso em: 22 out. 2013.

BRASIL. Ministério da Saúde. Secretaria da Vigilância Sanitária. Portaria SVS/MS no 326, de 30 de julho de 1997. Aprovar o Regulamento Técnico; "Condições Higiênicos-Sanitárias e de Boas Práticas de Fabricação para Estabelecimentos Produtores/Industrializadores de Alimentos". Brasília, DF, 1997. Disponível em:

<http://portal.anvisa.gov.br/wps/wcm/connect/cf430b80 4745808a8c95dc3fbc4c6735/Portaria+SVSMS+N.+326 + de+30+de+Julho+de+1997.pdf?MOD=AJPERES $>$. Acesso em: 22 out. 2013.
LAGEMANN, M. Agroindústrias Familiares como Alternativa de Renda para o Desenvolvimento dos Pequenos Municípios. Lajeado, 2001. 113 f. Monografia (Graduação) - Centro Universitário Univates, Curso de Ciências Econômicas, 2001.

REUNIÃO DO CODETER, 2., 2012, Encantado. Ata da II Reunião do Codeter. Encantado: Codeter, 2012.

REUNIÃO DO CODETER, 6., 2013, Fazenda Vilanova. Ata da VI Reunião do Codeter. Fazenda Vilanova: Codeter, 2013.

RIO GRANDE DO SUL. Lei $\mathbf{n}^{\mathbf{0}} \mathbf{1 3 . 8 3 9}$, de 5 de dezembro de 2011. Institui a Política Estadual de Fomento à Economia da Cooperação, cria o Programa de Cooperativismo, o Programa de Economia Popular e Solidária, o Programa Estadual de Fortalecimento das Cadeias e Arranjos Produtivos Locais, o Programa Gaúcho de Micro-crédito e o Programa de Redes de Cooperação, e dá outras providências. Porto Alegre, 2011. Disponível em:<http://www.mdic.gov.br/arquivos/dwnl_13353663 30.pdf>. Acesso em: 22 out. 2013.

SAMPIERI, R.H.; COLLADO, C.F.; LUCIO, M. Del P. B. Metodologia de pesquisa. 5.ed. Porto Alegre: Penso, 2013. 624p.

TONDO, E.C.; BARTZ, S. Microbiologia e Sistemas de Gestão da Segurança de Alimentos. Porto Alegre: Sulinas, 2011. 263 p. 